ISSN 0103-9954

\title{
RESISTÊNCIA NATURAL DE SEIS ESPÉCIES DE MADEIRAS DA REGIÃO AMAZÔNICA A FUNGOS APODRECEDORES, EM ENSAIOS DE LABORATÓRIO
}

\section{NATURAL DECAY RESISTANCE OF SIX AMAZON WOOD SPECIES IN SOIL BLOCK TESTS}

Marcus Vinicius da Silva Alves ${ }^{1}$ Alexandre Florian da Costa ${ }^{2}$ Daniele da Silva Espig ${ }^{3}$

\author{
Ailton Teixeira do Vale ${ }^{2}$
}

\section{RESUMO}

O presente trabalho avaliou a resistência natural das madeiras de Aspidosperma desmanthum (Araracanga), Parinari excelsa (Parinari), Mouriri callocarpa (Miraúba), Marmaroxylon racemosum (Angelim-rajado), Peltogyne paniculata (Roxinho) e Astronium sp. (Muiracatiara) aos fungos causadores de podridão-branca Pycnoporus sanguineus e podridão-parda Gloeophyllum trabeum, em ensaios de laboratório. A determinação da resistência natural foi feita por meio da avaliação da perda de massa, com base na norma da American Society for Testing and Materials - Standard Method for Accelerated Laboratory Test of Natural Decay Resistance of Woods - ASTM D2017/81(86). Todas as espécies se apresentaram muito resistentes aos fungos Pycnoporus sanguineus e Gloeophyllum trabeum, exceto Aspidosperma desmanthum que mostrou ser resistente ao fungo de podridão parda. A espécie Peltogyne paniculata mostrou-se a mais resistente ao fungo Pycnoporus sanguineus, enquanto Parinari excelsa apresentou-se como a espécie de menor resistência. A maior resistência ao fungo Gloeophyllum trabeum foi observada para a madeira de Astronium sp., enquanto que a espécie Aspidosperma desmanthum se mostrou como a menos resistente.

Palavras-chave: Madeiras da Amazônia; resistência natural; ensaio acelerado; fungos apodrecedores.

\section{ABSTRACT}

This study evaluated the natural resistance of six Amazonian wood species: Aspidosperma desmanthum (Araracanga), Parinari excelsa (Parinari), Mouriri callocarpa (Miraúba), Marmaroxylon racemosum (Angelim-rajado), Peltogyne paniculata (Roxinho) e Astronium sp. (Muiracatiara) against Pycnoporus sanguineous, a white rot fungus, and Gloeophyllum trabeum, a brown rot fungus. Testing was performed based on the American Society for Testing and Materials - Standard Method for Accelerated Laboratory Test of Natural Decay Resistance of Woods - ASTM D2017/81(86). Results showed that all tested wood species were classified as very resistant to both decay fungi, except the wood of Aspidosperma desmanthum, which demonstrated to be very resistant to Pycnoporus sanguineous and resistant to Gloeophyllum trabeum. The wood of Peltogyne paniculata showed the best performance against Pycnoporus sanguineous, whereas the wood of Astronium sp. presented the best results when submitted to Gloeophyllum trabeum attack.

Key words: amazonian woods; natural resistance; soil block test; decay fungi.

\section{INTRODUÇÃO}

A ampliação do aproveitamento da madeira, ocasionada pelos processos industriais, contribui para o rápido crescimento de sua demanda. Contudo, o aumento na utilização de um grupo reduzido de espécies tem contribuído, significativamente, para a escassez dessas espécies e o desperdício das florestas e matas nativas. As indústrias moveleiras e de madeira beneficiada estão cada vez mais dependentes das madeiras da região amazônica, como fonte principal de matéria-prima.

Dessa forma, a necessidade de estudos sobre a adequabilidade da madeira no seu emprego torna-se cada vez maior. Um dos fatores limitantes para a utilização de novas espécies florestais é a falta de dados sobre suas propriedades e, conseqüentemente, de seus possíveis usos comerciais e industriais.

1. Engenheiro Florestal, PhD., Pesquisador do Laboratório de Produtos Florestais, Instituto Brasileiro do Meio Ambiente (IBAMA), CEP: 70818-900, Brasília (DF).

2. Engenheiro Florestal, Dr., Professor Adjunto do Departamento de Engenharia Florestal, Universidade de Brasília, Caixa Postal 04357, CEP: 70.919-970, Brasília (DF).

3. Acadêmica do Curso de Graduação em Engenheira Florestal, Universidade de Brasília, Caixa Postal 04357, CEP: 70.919-970, Brasília (DF).

Recebido para publicação em 26/04/2005 e aceito em 12/02/2006. 
A madeira, em virtude da sua estrutura e constituição química, pode ser atacada por diversos agentes biológicos. Uma linha de ação economicamente viável para impedir o ataque desses agentes consiste na utilização de madeiras dotadas de elevada resistência natural.

Portanto, para se estabelecer critérios de usos de madeiras, é de importância primordial a obtenção de informações sobre sua durabilidade natural. $\mathrm{O}$ conhecimento da resistência natural da madeira possibilita sua utilização racional, contribuindo diretamente para a redução do seu consumo e, conseqüentemente, dos custos com a sua substituição e com a preservação das reservas naturais remanescentes.

Estudos sobre durabilidade natural de madeiras têm indicado espécies florestais alternativas àquelas tradicionalmente utilizadas, o que pode contribuir para a minimização dos problemas relacionados à exploração intensiva e seletiva em torno de determinadas espécies florestais. Além disso, poderão evitar perdas e prejuízos financeiros irreparáveis decorrentes de gastos com a reposição de madeiras deterioradas.

Este trabalho tem como objetivo promover um maior conhecimento sobre a resistência natural de seis espécies de madeiras oriundas da Região Amazônica, quando submetidas ao ataque dos fungos apodrecedores Pycnoporus sanguineus e Gloeophyllum trabeum, em ensaios de laboratório, contribuindo para a melhor utilização dessas espécies nativas.

\section{MATERIAL E MÉTODOS}

O trabalho foi realizado no Laboratório de Produtos Florestais (LPF) do Instituto Brasileiro do Meio Ambiente e dos Recursos Naturais Renováveis (IBAMA).

O ensaio de laboratório utilizado para avaliar a resistência natural das espécies de madeiras obedeceu à norma da American Society for Testing and Materials - Standard Method for Accelerated Laboratory Test of Natural Decay Resistance of Woods - ASTM D2017/81 (86), com as seguintes modificações:

a) os corpos-de-prova foram confeccionados em dimensões reduzidas ( 5 x 5 x $3 \mathrm{~mm}$ ), objetivando reduzir o tempo de exposição da madeira aos fungos xilófagos;

b) a climatização dos corpos-de-prova foi feita em estufa a $50 \pm 1^{\circ} \mathrm{C}$, por um período de 72 horas;

c) utilizou-se um fungo de podridão-branca (Pycnoporus sanguineus) e um de podridão parda (Gloeophyllum trabeum); e

d) a cultura dos fungos foi efetuada em meio líquido, contendo malte e água destilada.

\section{Espécies de madeira}

Foram selecionadas madeiras de seis espécies florestais oriundas da Região Amazônica (Tabela 1) com grande potencial de uso em substituição às tradicionalmente conhecidas.

TABELA 1: Espécies de madeiras selecionadas para o presente estudo.

TABLE 1: Selected wood species for laboratory testing.

\begin{tabular}{lll}
\hline \multicolumn{1}{c}{ Nome científico } & Nome popular & Família \\
\hline Aspidosperma desmanthum & Araracanga & Apocynaceae \\
Mouriri callocarpa & Miraúba & Melastomataceae \\
Parinari excelsa & Parinari & Chrysobalanaceae \\
Astronium sp. & Muiracatiara & Anarcadiaceae \\
Peltogyne paniculata & Roxinho & Caesalpiniaceae \\
Marmaroxylon racemosum & Angelim-rajado & Mimosaceae \\
\hline
\end{tabular}

Preparação dos corpos-de-prova

Os corpos-de-prova foram confeccionados nas dimensões de 5 × $5 \times 3 \mathrm{~mm}$, sendo a última dimensão orientada no sentido das fibras. Na Figura 1, são apresentadas ilustrações dos corpos-de-prova utilizados no ensaio de laboratório. Tais corpos-de-prova foram obtidos partindo do cerne, em virtude deste apresentar maior resistência ao ataque de fungos xilófagos.

Todas as amostras se apresentavam isentas de nós, gomas e resinas e receberam identificação numérica em cada uma de suas faces (tangencial, radial e transversal) com caneta de tinta impermeável. Foram selecionados cinqüenta corpos-de-prova para cada espécie de madeira, sendo distribuídas 25 amostras 
para cada um dos fungos da seguinte forma: cinco corpos de prova por frasco, contendo solo e placa suporte, e cinco frascos por espécie de madeira, para cada fungo.

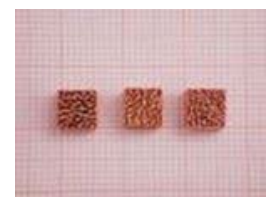

Marmaroxylon racemosum

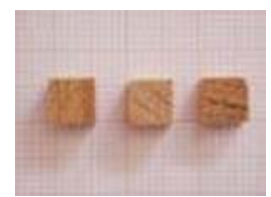

Aspidosperma desmanthum

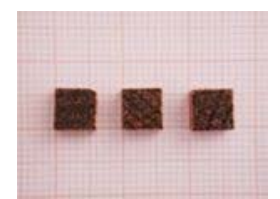

Mouriri callocarpa

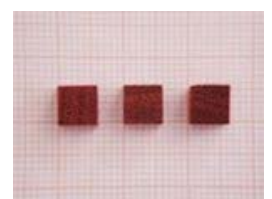

Astronium $s p$

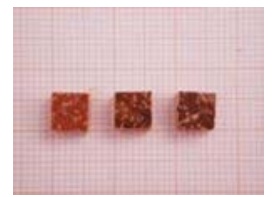

Parinari excelsa

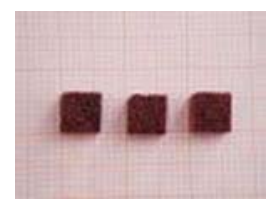

Peltogyne paniculata

FIGURA 1: Corpos-de-prova das espécies utilizadas no ensaio acelerado de laboratório.

FIGURE 1: Wood samples used in soil block testing.

\section{Espécies de fungos apodrecedores}

Foram utilizados os fungos Gloeophyllum trabeum (Pers. ex Fr.), causador de podridão-parda, e Pycnoporus sanguineus (Pers. ex Fr.) Murr., causador de podridão-branca. Os fungos foram obtidos partindo da repicagem de colônias puras mantidas pelo LPF/IBAMA.

\section{Preparo do substrato}

Como frascos, foram utilizados vidros redondos com tampa rosqueável, com capacidade de $150 \mathrm{ml}$ em volume líquido.

O solo utilizado como substrato foi latossolo vermelho, coletado de horizonte B, proveniente da Fazenda Água Limpa, pertencente à Universidade de Brasília. O solo foi analisado, tendo seu pH corrigido para 6,38 utilizando-se calcário dolomítico PRNT (66\%), na proporção de $65 \mathrm{~g}$ para cada $20 \mathrm{~kg}$ de solo. O solo foi peneirado em peneira de $3 \mathrm{~mm}$ de abertura para a eliminação de impurezas e quebra dos torrões.

A quantidade de água adicionada nos frascos foi obtida com base na seguinte expressão:

$$
Q A=[1,30 \times(A-B)] \times[D \div(100+B)]
$$

Em que: $Q A=$ Quantidade de água a ser adicionada (g); $A$ = Capacidade de Retenção de Água do solo (\%); $B=$ Conteúdo de umidade do solo seco ao ar (\%); $D=$ Quantidade de solo seco a ser adicionada nos frascos (g).

A capacidade de retenção de água do solo (C.R.A.S.) foi obtida partindo de um valor prédeterminado para o latossolo vermelho que se apresentava em torno de $38 \%$.

O teor de umidade inicial do solo foi obtido por meio da porcentagem de peso perdido após 24 horas em estufa a $103 \pm 2^{\circ} \mathrm{C}$, utilizando-se a seguinte expressão:

$$
T U(\%)=\frac{\text { peso inicial }- \text { peso final }}{\text { peso final }} \times 100
$$

Foram secos em estufa $50 \mathrm{~g}$ do solo a ser utilizado no teste acelerado, obtendo-se um teor de umidade de $9,0 \%$.

Em cada frasco de vidro, foram adicionados $70 \mathrm{~g}$ de solo e $24 \mathrm{ml}$ de água destilada. Cada vidro recebeu uma placa suporte de madeira nas dimensões de $0,3 \times 2,9 \times 3,5 \mathrm{~cm}$ de alburno de espécies suscetíveis aos fungos xilófagos utilizados. Essa placa suporte foi colocada sobre o solo no interior do vidro, servindo de substrato para o desenvolvimento dos fungos. Foram utilizadas placas suporte de embaúba (Cecropia sp.) e pinus (Pinus sp.), em decorrência do fungo Pycnoporus sanguineus apresentar um melhor desenvolvimento sobre espécies de folhosas e o fungo Gloeophyllum trabeum sobre espécies de coníferas, respectivamente.

Após a preparação dos frascos de vidro, estes foram autoclavados a $120^{\circ} \mathrm{C}$ e pressão de uma atmosfera durante uma hora sendo, posteriormente, acondicionados em sala de incubação à temperatura de $27 \pm 1^{\circ} \mathrm{C}$ e umidade relativa de $70 \pm 4 \%$, durante um mês. 


\section{Repicagem dos fungos}

Durante o período de acondicionamento dos frascos de vidros na sala de incubação, foi efetuada a repicagem dos fungos em meio de cultura líquido. O meio de cultura foi preparado utilizando-se água destilada e malte, na proporção de $15 \mathrm{~g}$ de malte para $1000 \mathrm{ml}$ de água destilada. Foram preparados $200 \mathrm{ml}$ de meio de cultura líquida para a inoculação dos fungos, sendo adicionados $100 \mathrm{ml}$ em cada frasco do tipo Erlenmeyer. Após a preparação, o meio de cultura foi agitado em um aparelho Mixer Ética - Mod 114, por um período de 5 minutos, para proporcionar uma maior homogeneidade, sendo posteriormente autoclavado a $120^{\circ} \mathrm{C}$ e pressão de uma atmosfera durante 20 minutos.

A repicagem dos fungos foi feita em capela de fluxo laminar. Procurou-se obter inóculos de aproximadamente $1 \mathrm{~cm}^{2}$, contendo micélios do fungo, que foram adicionados ao meio de cultura líquido. Os frascos inoculados foram levados para uma mesa agitadora do tipo Nova Técnica N/145, por um período de 48 horas, com o objetivo de proporcionar uma aeração ao meio de cultura. A seguir, os frascos foram mantidos em sala de incubação à temperatura de $27 \pm 1^{\circ} \mathrm{C}$ e umidade relativa de $70 \pm 4 \%$ por um período de 15 dias, para um melhor desenvolvimento do fungo.

\section{Inoculação e incubação dos fungos}

Antes da inoculação dos vidros, o meio de cultura foi transferido para o copo de um triturador no qual foi levemente batido. Esse procedimento possibilitou uma distribuição homogênea dos micélios do fungo no meio de cultura. A inoculação dos vidros foi efetuada em capela asséptica utilizando-se um pipetador, com o qual foram colocados $3 \mathrm{ml}$ do meio de cultura líquido contendo micélios de fungo, entre a placa suporte e o solo.

Depois de inoculados, os vidros retornaram à sala de incubação onde permaneceram por um período de 30 dias, necessários para que o micélio do fungo cobrisse homogeneamente a superfície do substrato (placa suporte).

\section{Climatização e esterilização dos corpos-de-prova}

Para obtenção da massa inicial, antes do ataque dos fungos, os corpos-de-prova foram climatizados em estufa a $50 \pm 1{ }^{\circ} \mathrm{C}$ por um período de 72 horas, possibilitando que os resultados ao final do ataque dos fungos fossem obtidos nas mesmas condições.

Efetuada a climatização, os corpos-de-prova foram colocados em um dessecador contendo sílica, por aproximadamente 15 minutos, sendo, então, pesados.

Antes da inoculação, os corpos-de-prova foram esterilizados objetivando eliminar organismos cujas ações não seriam avaliadas no experimento. A esterilização foi efetuada em autoclave a uma temperatura de $110 \pm 10^{\circ} \mathrm{C}$ por um período de uma hora.

\section{Inoculação dos corpos-de-prova e período de ataque dos fungos}

Nessa etapa, os corpos-de-prova foram assepticamente introduzidos, com o auxílio de uma pinça, nos frascos de vidro contendo o fungo. Os corpos-de-prova foram uniformemente distribuídos sobre a placa suporte, sendo colocados cinco corpos-de-prova em contato com o fungo em cada frasco de vidro, sendo tal procedimento repetido para cada espécie de madeira e de fungo.

Terminada a inoculação dos corpos-de-prova, os frascos retornaram à sala de incubação onde permaneceram por um período de 6 semanas.

\section{Retirada dos corpos-de-prova}

Decorrido o período de ataque dos fungos, os corpos-de-prova foram retirados dos frascos de vidro e cuidadosamente limpos com o auxílio de um pincel, para remoção dos micélios de fungo acumulados em sua superfície. Posteriormente, os corpos-de-prova foram novamente climatizados, em estufa a $50 \pm 1^{\circ} \mathrm{C}$ por 72 horas, sendo pesados, para obter suas massas após o período de exposição ao ataque dos fungos.

\section{Avaliação da perda de massa}

O grau de resistência natural de cada corpo-de-prova de madeira foi avaliado em função da sua perda de massa (pm). 
De posse dos dados referentes à massa inicial e final dos corpos-de-prova, a resistência das diferentes espécies estudadas foi determinada em termos da média de percentagem de perda de massa, por meio da seguinte equação:

$$
\text { pm }(\%)=\frac{\text { massa inicial }- \text { massa final }}{\text { massa inicial }} \times 100
$$

A classificação da resistência natural das espécies de madeiras foi determinada de acordo com a norma ASTM D 2017/ 81 (86), conforme apresentado na Tabela 2.

TABELA 2: Classificação da resistência natural de madeiras submetidas ao ataque de fungos apodrecedores em ensaio acelerado em laboratório.

TABLE 2: Classification of the natural resistance of wood species submitted to an accelerated decay testing.

\begin{tabular}{cl}
\hline Média de Massa Perdida (\%) & Classificação \\
\hline $0-10$ & Muito resistente \\
$11-24$ & Resistente \\
$25-44$ & Moderadamente resistente \\
$>45$ & Pouco ou não-resistente \\
\hline
\end{tabular}

\section{Análises estatísticas}

Os resultados obtidos de perda de massa dos corpos-de-prova de madeira, expressos em percentagem, foram analisados estatisticamente pelo Programa GENES (Cruz, 2001).

As análises estatísticas foram realizadas ao nível de significância de 5\% de probabilidade. Para avaliar a resistência natural das madeiras, utilizou-se a análise de variância fatorial em um experimento inteiramente casualizado com dois fatores: fungos com dois níveis (podridão-branca e podridão-parda), espécie de madeira com seis níveis (araracanga, parinari, muiracatiara, miraúba, roxinho e angelim-rajado) e a interação entre esses fatores. Para cada combinação fungo x espécie de madeira, foram feitas 25 repetições inteiramente ao acaso. A variável avaliada na análise de variância foi a perda de massa em relação à massa inicial. O modelo fatorial de análise de variância possibilita verificar se os fatores têm efeito significativo sobre as variáveis e se há interação entre os fatores.

Para a comparação múltipla das médias, utilizou-se o Teste de Tukey (Tukey honest significant difference test) ao nível de 5\% de probabilidade.

\section{RESULTADOS E DISCUSSÃO}

As Tabelas 3 e 4 apresentam os valores médios da massa específica, da massa perdida em gramas e em percentagem e a classificação da resistência natural segundo a norma ASTM D2017/86 das seis espécies de madeiras, após o ataque dos fungos Pycnoporus sanguineus e Gloeophyllum trabeum respectivamente.

TABELA 3: Valores médios de massa específica, de massa perdida e classificação da resistência natural das madeiras submetidas ao ataque do fungo Pycnoporus sanguineous.

TABLE 3: Average wood density, weight loss and classification of the natural resistance of wood species submitted to the fungus Pycnoporus sanguineous.

\begin{tabular}{|c|c|c|c|c|}
\hline \multirow[b]{2}{*}{ Espécies } & \multirow{2}{*}{$\begin{array}{l}\text { Massa } \\
\text { Específica } \\
\left(\mathrm{g} / \mathrm{cm}^{3}\right)\end{array}$} & \multicolumn{2}{|c|}{ Massa Perdida } & \multirow{2}{*}{$\begin{array}{l}\text { Classificação da Resistência } \\
\text { Natural }^{1}\end{array}$} \\
\hline & & Gramas & $\%$ & \\
\hline Aspidosperma desmanthum & 0,82 & 0,0011 & 2,43 & Muito Resistente \\
\hline Parinari excelsa & 0,92 & 0,0026 & 3,21 & Muito Resistente \\
\hline Mouriri callocarpa & 1,09 & 0,0007 & 0,58 & Muito Resistente \\
\hline Marmaroxylom racemosum & 0,99 & 0,0022 & 2,06 & Muito Resistente \\
\hline Peltogyne paniculata & 1,00 & 0,0001 & 0,05 & Muito Resistente \\
\hline Astronium sp. & 0,93 & 0,0028 & 2,32 & Muito Resistente \\
\hline
\end{tabular}

Em que: 1 = Segundo ASTM D 2017/86 
TABELA 4: Valores médios de massa específica, de massa perdida e classificação da resistência natural das madeiras submetidas ao ataque do fungo Gloeophyllum trabeum.

TABLE 4: Average wood density, weight loss and classification of the natural resistance of wood species submitted to the fungus Gloeophyllum trabeum.

\begin{tabular}{l|c|c|c|c}
\hline \multirow{2}{*}{ Espécies } & \multirow{2}{*}{\begin{tabular}{c} 
Massa \\
Específica \\
\cline { 3 - 4 }
\end{tabular}} & \multicolumn{2}{c|}{ Massa Perdida } & \multirow{2}{*}{ Classificação da Resistência $\left._{\text {Natural }}{ }^{3}\right)$} \\
\hline Aspidosperma desmanthum & 0,82 & 0,0097 & 12,12 & Resistente \\
Parinari excelsa & 0,92 & 0,0071 & 7,13 & Muito Resistente \\
Mouriri callocarpa & 1,09 & 0,0051 & 4,58 & Muito Resistente \\
Marmaroxylom racemosum & 0,99 & 0,0082 & 7,63 & Muito Resistente \\
Peltogyne paniculata & 1,00 & 0,0052 & 4,88 & Muito Resistente \\
Astronium sp. & 0,93 & 0,0024 & 1,97 & Muito Resistente \\
\hline
\end{tabular}

Em que: 1 = Segundo ASTM D 2017/86

\section{Ataque dos fungos apodrecedores}

A análise do comportamento dos fungos mostrou um desenvolvimento mais rápido do Pycnoporus sanguineus em relação ao Gloeophyllum trabeum. Eaton \& Hale (1993) mencionam que o fungo Gloeophyllum trabeum apresenta um crescimento com períodos de repouso, o que demonstra seu desenvolvimento mais lento.

No entanto, o fungo Gloeophyllum trabeum apresentou uma intensidade de ataque maior, visto que os valores médios de perda de massa das madeiras foram sempre superiores quando submetidas ao fungo de podridão parda, exceto para a espécie Astronium sp. Lepage (1986) comenta que a podridão parda, em geral, provoca uma diminuição nas características físicas da madeira mais rapidamente que a podridão-branca.

Avaliando-se a percentagem de perda de massa, pode-se verificar que a intensidade de ataque dos fungos utilizados variou de acordo com a espécie de madeira. Eaton \& Hale (1993) discutem que a resistência natural da madeira está condicionada às vias de acesso para os fungos e à composição química das madeiras, sendo esta uma característica que varia substancialmente entre espécies e, inclusive, dentro da mesma árvore.

\section{Resistência natural das espécies de madeiras}

Comparando-se os valores de perda de massa das espécies de madeiras pôde-se verificar que estas apresentaram comportamentos distintos diante do ataque dos fungos. Lepage (1986) comenta que a madeira, por ser um material de durabilidade natural relativa, pode apresentar, com freqüência, diferenças quanto à sua resistência a fungos apodrecedores.

Todas as espécies de madeira, exceto Parinari excelsa, apresentaram valores médios de perda de massa, diante do ataque do fungo Pycnoporus sanguineus, abaixo de $3 \%$.

Com relação à perda de massa decorrente do ataque do fungo Gloeophyllum trabeum,todas as espécies, com exceção da Astronium sp., apresentaram perdas superiores a 4,0\%.

A espécie Peltogyne paniculata apresentou a menor perda de massa em conseqüência do ataque do fungo Pycnoporus sanguineus, entretanto, diante do ataque do Gloeophyllum trabeum, a espécie Astronium sp. mostrou-se a mais resistente. Segundo Oliveira et al. (1986), a resistência à deterioração pode ser atribuída em grande parte à presença de taninos e outras substâncias fenólicas complexas, presentes na madeira, as quais são tóxicas a determinados fungos xilófagos.

A diferença de resistência natural entre as espécies de madeiras, em relação aos fungos Pycnoporus sanguineus e Gloeophyllum trabeum, foi mais marcante para Aspidosperma desmanthum. Essa espécie de madeira apresentou uma perda de massa de $2,43 \%$, quando submetida ao ataque do fungo de podridãobranca, e de $12,12 \%$ quando submetida ao fungo de podridão-parda. Isso reflete, de acordo com Bravery (1987), as diferentes características fisiológicas e necessidades nutricionais dos organismos xilófagos, os quais demonstram preferências por determinadas espécies de madeira conforme sua composição química.

As espécies Aspidosperma desmanthum, Marmaroxylom racemosum e Astronium sp. apresentaram 
uma resistência natural similar em relação ao fungo de podridão-branca, com uma perda média de massa de $2,43,2,06$ e $2,32 \%$ respectivamente.

As espécies Parinari excelsa e Marmaroxylom racemosum mostraram uma resistência semelhante em relação ao fungo Gloeophyllum trabeum, com uma perda média de massa de 7,13 e 7,63\% respectivamente. Já as espécies Mouriri callocarpa e Peltogyne paniculata apresentaram uma perda de massa de 4,58 e 4,88 respectivamente diante do mesmo fungo.

Uma análise visual não mostrou alterações estéticas nas amostras testadas, após o período de ataque do fungo Pycnoporus sanguineus, quando comparado ao seu aspecto antes de serem submetidas ao ataque. Contudo, as amostras submetidas ao Gloeophyllum trabeum apresentaram, após o período de ataque do fungo, superfícies levemente escurecidas.

De maneira geral, não foi observada uma relação entre a resistência natural das espécies de madeiras com as suas massas específicas. Quirino et al. (1982) estudando a resistência natural de quatro espécies de madeiras frente ao ataque de fungo apodrecedor não observaram também relação entre a massa específica e a resistência natural das madeiras, verificando que essa resistência se deveu às variações de extrativos entre as espécies.

Apesar da percentagem média de perda de massa ter sido diferente entre as espécies, estas foram classificadas como muito resistentes aos fungos testados conforme a ASTM D2017/86, com exceção da espécie Aspidosperma desmanthum que passou de muito resistente, quando submetida ao fungo de podridão-branca, para resistente ao fungo de podridão-parda.

De acordo com a ASTM D-2017/86, uma madeira pode ser considerada muito resistente quando apresenta uma perda de massa inferior a $10 \%$. Dessa forma, as espécies testadas apresentaram os seguintes resultados:

- Aspidosperma desmanthum se apresentou muito resistente ao fungo Pycnoporus sanguineus, e resistente ao fungo Gloeophyllum trabeum. Cardias (1985), observou um resultado semelhante trabalhando com a espécie Aspidosperma polyneuron diante do fungo Pycnoporus sanguineus. No entanto, Monteiro (1997), trabalhando com a mesma espécie (A. polyneuron), observou uma baixa resistência diante do fungo Gloeophyllum trabeum.

- Mouriri callocarpa, Parinari excelsa, Marmaroxylon racemosum e Peltogyne paniculata mostraram-se muito resistentes aos fungos Pycnoporus sanguineus e Gloeophyllum trabeum.

- Astronium sp. se mostrou muito resistente aos fungos Pycnoporus sanguineus e Gloeophyllum trabeum. Monteiro (1997), trabalhando com a mesma espécie, observou um comportamento semelhante quando submetida ao ataque do Gloeophyllum trabeum. Já Cardias (1985), trabalhando com Astronium gracile, de massa específica $1,14 \mathrm{~g} / \mathrm{cm}^{3}$, observou que a espécie se mostrou altamente resistente ao fungo Pycnoporus sanguineus.

Em estudos com outras espécies oriundas da região amazônica (Erisma uncinatum e Enterolobium schamburgkii), Cardias (1985) observou que estas se apresentaram muito resistentes aos fungos Pycnoporus sanguineus e Gloeophyllum trabeum.

\section{Análise estatística}

A análise de variância mostrou que a interação entre o fungo e a espécie de madeira foi significativa a 5\% de probabilidade. Os resultados mostram que a intensidade de ataque dos fungos está relacionada com a espécie de madeira atacada, e que a resistência das espécies de madeiras dependeu do tipo de fungo, conforme apresentado na Tabela 5. 
TABELA 5: Análise de variância das espécies de madeiras, fungos e interação.

TABLE 5: Statistical analysis for wood species, fungi and their interactions.

\begin{tabular}{l|c|c|c|c|c}
\hline FV & GL & SQ & QM & F & Significância \\
\hline Fungo & 1 & 1106,093 & 1106,093 & $580,47^{*}$ & 0,0000 \\
Espécie de madeira & 5 & 1093,977 & 218,7954 & $114,8^{*}$ & 0,0000 \\
Fungo x madeira & 5 & 684,4698 & 136,8940 & $71,84^{*}$ & 0,0000 \\
Resíduo & 288 & 548,7994 & 1,9055 & & \\
\hline
\end{tabular}

Em que: * = Diferença entre as médias significativa a $5 \%$ de probabilidade.

Apesar da interação entre o fungo e a espécie de madeira ter sido significativa, em todas as espécies de madeiras estudadas, o fungo Gloeophyllum trabeum apresentou a maior intensidade de ataque.

O resultado da análise de variância do efeito do fungo Pycnoporus sanguineus, sobre as espécies de madeiras testadas, mostrou que a intensidade de ataque desse fungo difere significativamente entre as espécies de madeiras, conforme apresentado na Tabela 6.

TABELA 6: Análise de variância do efeito do fungo Pycnoporus sanguineus sobre as espécies de madeira.

TABLE 6: Statistical analysis of the fungus Pycnoporus sanguineus effect on the resistance of wood species.

\begin{tabular}{lccccc}
\hline FV & GL & SQ & QM & F \\
\hline Espécie de madeira & 5 & 196,368 & 39,273 & $140,17^{*}$ \\
Resíduo & 144 & 40,35 & 0,2801 & \\
\hline Eno
\end{tabular}

Em que: $*$ = Diferença entre as médias significativa a $5 \%$ de probabilidade.

A perda de massa das espécies de madeiras submetidas ao ataque do fungo Pycnoporus sanguineus pelo teste de Tukey de comparação múltipla de médias é apresentado na Tabela 7.

TABELA 7: Comparação pelo Teste de Tukey das médias de perda de massa das espécies submetidas ao ataque do fungo Pycnoporus sanguineus.

TABLE 7: Tukey Test for average weight losses caused by Pycnoporus sanguineus decay.

\begin{tabular}{l|c|c}
\hline Espécies & N. de dados & Médias (\%) \\
\hline Parinari excelsa & 25 & $3,21 \mathrm{a}$ \\
Aspidosperma desmanthum & 25 & $2,43 \mathrm{~b}$ \\
Astronium sp. & 25 & $2,32 \mathrm{~b}$ \\
Marmaroxylom racemosum & 25 & $2,06 \mathrm{~b}$ \\
Mouriri callocarpa & 25 & $0,58 \mathrm{c}$ \\
Peltogyne paniculata & 25 & $0,05 \mathrm{~d}$ \\
\hline
\end{tabular}

Médias seguidas pela mesma letra não diferem estatisticamente.

Os resultados mostram que as perdas de massas de Astronium desmanthum, Astronium sp. e M. racemosum foram significativamente diferentes em relação a Pycnoporus excelsa, Mouriri callocarpa e Pycnoporus paniculata.

Entre as espécies Astronium desmanthum, Astronium sp. e Marmaroxylom racemosum, a perda de massa não foi significativamente diferente. No entanto, as perdas de massas entre as espécies Parinari excelsa, Mouriri callocarpa e Pycnoporus paniculata foram significativamente diferentes.

A perda de massa da espécie Peltogyne paniculata foi menor em comparação com as demais espécies, demonstrando ser esta a mais resistente ao fungo Pycnoporus sanguineus.

A análise de variância do efeito do fungo Gloeophyllum trabeum, sobre as espécies de madeiras estudadas (Tabela 8), mostrou que houve diferença significativa de intensidade de ataque dos fungos sobre as espécies de madeiras. 
TABELA 8: Análise de variância do efeito do fungo Gloeophyllum trabeum sobre as espécies de madeira. TABLE 8: Statistical analysis of the fungus Gloeophyllum trabeum effect on the resistance of wood species.

\begin{tabular}{lccccc}
\hline FV & GL & SQ & QM & F \\
\hline Espécie de madeira & 5 & 1841,37 & 368,27 & $97,341^{*}$ \\
Resíduo & 144 & 544,79 & 3,783 & \\
\hline
\end{tabular}

Em que: $*$ = Diferença entre as médias significativa a $5 \%$ de probabilidade.

As perdas de massas das espécies de madeiras submetidas ao ataque do fungo Gloeophyllum trabeum analisadas pelo teste de Tukey de comparação múltipla de médias são apresentadas na Tabela 9.

TABELA 9: Comparação pelo Teste de Tukey das médias de perda de massa das espécies submetidas ao Gloeophyllum trabeum.

TABLE 9: Tukey Test for average weight losses caused by Gloeophyllum trabeum decay.

\begin{tabular}{l|c|c}
\hline Espécies & N. de Dados & Médias (\%) \\
\hline Aspidosperma desmanthum & 25 & $12,12 \mathrm{a}$ \\
Marmaroxylom racemosum & 25 & $7,63 \mathrm{~b}$ \\
Parinari excelsa & 25 & $7,13 \mathrm{~b}$ \\
Peltogyne paniculata & 25 & $4,88 \mathrm{c}$ \\
Mouriri callocarpa & 25 & $4,58 \mathrm{c}$ \\
Astronium sp. & 25 & $1,97 \mathrm{~d}$ \\
\hline
\end{tabular}

Médias seguidas pela mesma letra não diferem estatisticamente.

Os resultados mostram que as perdas de massas entre as espécies Marmaroxylom racemosum e Pycnoporus excelsa não foram significativamente diferentes. Da mesma forma, as perdas de massas entre as espécies Mouriri callocarpa e Pycnoporus paniculata não foram significativamente diferentes entre si, porém, houve diferença em relação às duas espécies de madeiras anteriores.

A maior perda de massa foi observada na espécie Aspidosperma desmanthum, demonstrando ser esta a mais susceptível ao fungo Gloeophyllum trabeum, enquanto a espécie Astronium sp. apresentou a menor perda de massa, demonstrando ser esta a mais resistente, dentre as seis espécies, a esse fungo. Ambos os resultados diferiram significativamente em relação aos das demais espécies de madeiras.

\section{CONCLUSÕES}

Todas as espécies apresentaram-se muito resistentes aos fungos apodrecedores Pycnoporus sanguineus e Gloeophyllum trabeum, exceto Aspidosperma desmanthum que mostrou ser resistente ao fungo de podridão-parda.

A espécie Peltogyne paniculata mostrou ser a mais resistente ao fungo de podridão branca Pycnoporus sanguineus, seguida pela espécie Mouriri callocarpa.

A madeira de Parinari excelsa apresentou a menor resistência ao fungo Pycnoporus sanguineus.

As resistências das madeiras de Aspidosperma desmanthum, Astronium sp. e Marmaroxylom racemosum ao fungo Pycnoporus sanguineus não apresentaram diferenças significativas a $5 \%$ de probabilidade.

A espécie Astronium sp. se mostrou a mais resistente ao fungo Gloeophyllum trabeum, enquanto a espécie Aspidosperma desmanthum mostrou ser a menos resistente a esse fungo.

As espécies Marmaroxylom racemosum e Parinari excelsa apresentaram resistências semelhantes ao fungo Gloeophyllum trabeum, fato esse observado também entre as espécies Mouriri callocarpa e Peltogyne paniculata, porém, com níveis de perda de massa diferentes.

As madeiras das espécies Aspidosperma desmanthum, Parinari excelsa, Mouriri callocarpa, Astronium sp, Peltogyne paniculata e Marmaroxylom racemosum demonstraram grande potencial de uso em substituição às tradicionalmente utilizadas, no que se refere à durabilidade natural aos fungos de podridão estudados.

Não foi observada relação entre a resistência natural das espécies e suas respectivas massas específicas, indicando que o fato da madeira ser densa, não assegura uma boa resistência natural a fungos 
xilófagos.

\section{REFERÊNCIAS BIBLIOGRÁFICAS}

ALVES, M. V.S. Preservation of wood against fungal attack with lignins and ligninmetal complexes. 1996.178p. Dissertation (Doctor of Philosophy in Forestry) - University of Wisconsin, Madison, 1996.

AMERICAN SOCIETY FOR TESTING AND MATERIALS. Standard method for accelerated laboratory test of natural decay resistance for woods. Local : ASTM, 1981. p.2017-2081. (ASTM, v. 86)

BRAVERY, A.F. A miniaturised wood-block test for the rapid evaluation of wood preservatives fungicides. In: ANNUAL MEETING. Stockholm, 1987.

CARDIAS, M.F. Durabilidade natural de algumas espécies de madeiras brasileiras. Manaus : CPPF, 1985.150 p.

CRUZ, C.D. Programa genes : aplicativo computacional em genética e estatística. Viçosa : Editora UFV, 2001.648 p.

EATON, R.A.; HALE, M.D.C. Wood: deacy, pests and protection. London : Chapman \& Hall, 1993. 546 p.

FONSECA, N.M.E. Durabilidade de cinco espécies florestais na presença de dois fungos apodrecedores. Brasília, 1989. 21 p. Projeto final de graduação em Engenharia Florestal, UnB. Mimeografado.

LEPAGE, E.S. Manual de preservação de madeiras. São Paulo: IPT, 1986. 1v. (IPT - Publicação, 1637).

MONTEIRO, M.B.B. Método alternativo de ensaio acelerado para avaliação da resistência natural de madeiras ao ataque de fungos apodrecedores. 1997. 73 f. Dissertação (Mestrado) - Universidade de São Paulo, São Paulo, 1997.

OLIVEIRA, A.M.F; LELIS, A.T.; LEPAGE, E.S.; LOPEZ, G.A.C.; OLIVEIRA, L.C.S.; CAÑEDO, M.D.; MILANO, S. Agentes destruidores da madeira. In: Manual de preservação de madeiras. São Paulo: IPT, 1986. 1v., p. $102-107$. (IPT - Publicação, 1637).

QUIRINO, W.F.; NAKAMURA, R.M.; LISBOA, C.D.J.; BRITO, C.T. Resistência da madeira de quatro espécies florestais ao ataque do fungo Trichoderma viride Pers et S. F. Gray. Brasília: IBDF, 1982. 11 p. (Série Técnica, n. 3. Instituto Brasileiro de Desenvolvimento Florestal, Laboratório de Produtos Florestais) 